\title{
EDUCAÇÃO, GÊNERO E GERAÇÃO: O PERFIL DAS ESTUDANTES DO PROEJA/FIC DO IFPR/PARANAGUÁ ${ }^{1}$
}

\author{
EDUCATION, GENDER AND GENERATION: THE PROFILE OF STUDENTS \\ PROEJA / FIC`s IFPR / PARANAGUÁ
}

\author{
Nádia Terezinha Covolan ${ }^{2}$ \\ Maria Lucia Büher Machado ${ }^{3}$
}

\section{Resumo}

O artigo apresentado é resultado de parte do projeto de pesquisa financiado pelo CNPQ, voltado para a investigação sobre a inserção, permanência e empoderamento de alunas e alunos do PROEJA, no IFPR, Câmpus Paranaguá, no litoral paranaense. ${ }^{4}$ Nesse texto, analisamos especificamente o perfil das alunas participantes do PROEJA/ FIC do Ensino Fundamental. O perfil foi elaborado a partir de questionários aplicados em sala, na turma composta por 15 alunas e 2 alunos, em maio de 2012; num segundo momento, realizamos entrevistas com questões semiestruturadas. Dois pontos nos instigaram como dados de pesquisa - o fato das mulheres serem a grande maioria no curso, somada a especificidade da faixa etária - $80 \%$ do grupo feminino tem entre 39 e 63 anos, todas em fase de letramento. Dessa forma, enfocamos neste artigo, especialmente, as mulheres estudantes, analisando as suas percepções acerca das transformações ocorridas com elas e em suas vidas, a partir da retomada dos estudos. Nesse sentido, discutimos sobre as possibilidades e limites da política educacional do PROEJA/FIC para o empoderamento feminino. Os resultados indicam que aprender a ler, escrever e fazer contas, mesmo que tardiamente, é decisivo para o aumento da autonomia e do poder decisório feminino e pode, assim, impactar para uma vida mais digna e com maior acesso aos bens socialmente produzidos.

Palavras-chave: PROEJA/FIC, Gênero, Geração.

\footnotetext{
Artigo recebido em 01/10/2012 e aprovado em 31/10/2012.

1 PROEJA (Programa de Educação de Jovens e Adultos). Trata-se do Programa Nacional de Integração da Educação Básica com a Educação Profissional na Modalidade de Educação de Jovens e Adultos. O PROEJA/FIC (Formação Inicial e Continuada) é parte desse Programa e é realizado com os estudantes da Educação de Jovens e Adultos que estão cursando o Ensino Fundamental ou Médio. A carga horária dos cursos Proeja FIC é de 1400, sendo 1200 das disciplinas de conhecimento geral, e 200h da Formação Inicial e Continuada. Ao longo do artigo abordamos as especificidades do PROEJA/FIC e do PROEJA/Técnico, este destinado exclusivamente aos estudantes do Ensino Médio.

2 Doutora em Ciências Humanas (UFSC). Docente da UFPR - Setor Litoral. E-mail: nadiathe@ gmail.com.

${ }^{3}$ Doutora em Educação (UNICAMP). Docente do IFPR - Paranaguá. E-mail: lucia.buher@ifpr.edu.br.

4 Edital MCT/CNPq/SPM-PR/MDA N 020/2010: Pesquisas em temas de Relações de Gênero, Mulheres e Feminismos. Integra essa equipe a pesquisadora Rosana Jammal Padilha. Agradecemos a bolsista PBIS/IFPR Ana Paula Nunes pela sistematização dos dados dos questionários.
}

Divers@ Revista Eletrônica Interdisciplinar/Matinhos/Vol.5, n.2, p.1-136/jul./dez./2012 


\begin{abstract}
The paper presented results from part of a research project funded by $\mathrm{CNPq}$, focusing on research on the inclusion, retention and empowerment of women student from the PROEJA in IFPR, Campus Paranaguá, in Paraná coast. In this text we analyzed the profile of the students participating in the PROEJA/FIC Elementary School. The profile has been compiled from questionnaires administered in the classroom, the class comprised of 15 students women and 2 students man in May 2012; a second phase, we conducted semi structured interviews with issues. Two points have inspired us to research data - the fact that women are the majority in the course, plus the specific age group $-80 \%$ of women have between 39 and 63 years, all being literacy. Thus, we focus in this article, especially women students, examining their perceptions of changes occurring with them and their lives, from the resumption of studies. Accordingly, we discuss the possibilities and limits of educational policy PROEJA/FIC for female empowerment. The results indicate that learning to read, write and do arithmetic, even if belatedly, is decisive for increased autonomy and decision making power of women and can thus impact for a better life and greater access to socially produced goods.
\end{abstract}

Keywords: PROEJA/FIC, Gender, Geration

\title{
Introdução
}

$\mathrm{O}$ universo pesquisado se insere em movimentos de políticas educacionais que se aproximam no contexto da primeira década do século XXI - o primeiro foi o da criação dos Institutos Federais de Educação, Ciência e Tecnologia como instituições de educação superior, básica e profissional, a partir da Lei 11892/2008, marcado pelo processo de reorganização da Rede Federal de Educação Profissional, Científica e Tecnológica.

O segundo movimento foi o da implantação do PROEJA (Programa de Educação de Jovens e Adultos) pelo Governo Federal, a partir do Decreto 5478/2005, voltado inicialmente para o oferecimento de educação técnica profissional de nível médio, estabelecendo como base para o seu desenvolvimento a Rede Federal de Educação Profissional e Tecnológica, na qual se insere o IFPR - campus Paranaguá, localizado no litoral paranaense.

Dessa forma, a partir dessas configurações, direcionamos nosso foco para o estudo da organização e desenvolvimento dos cursos voltados especificamente para Jovens e Adultos no IFPR buscando investigar algumas questões: Como e até que ponto as relações sociais de gênero, imbricadas com as questões étnicas / raciais, geracionais e de classe implicam na inserção, permanência e possibilidades de empoderamento para as alunas e alunos Divers@ Revista Eletrônica Interdisciplinar/Matinhos/Vol.5, n.2, p.1-136/jul./dez./2012 
matriculados/as nos cursos do PROEJA do Instituto Federal de Ciência, Educação e Tecnologia do Paraná, campus Paranaguá, no litoral paranaense?

Em relação especificamente aos cursos do PROEJA, o campus Paranaguá, oferta em sua sede os cursos de Eletromecânica e Logística integrado ao Ensino médio. Além desses cursos, oferece em parceria com a Prefeitura Municipal de Pontal do Paraná o curso ProejaFIC (Formação Inicial Continuada) em Pesca e Aquicultura integrado ao Ensino Fundamental das séries iniciais, com aulas em uma Escola daquele Município.

O recorte estabelecido para esta comunicação é apresentar o perfil das alunas participantes do PROEJA/ FIC do Ensino Fundamental, bem como a análise das suas percepções acerca das transformações ocorridas a partir da retomada dos estudos no cotidiano do grupo analisado. Os instrumentos de pesquisa utilizados foram questionários fechados com o objetivo de traçar o perfil socioeconômico do grupo, e, em um segundo momento, a realização de entrevistas semiestruturadas. Para estas, foram respeitados os trâmites do Consentimento Informado e Esclarecido conforme a Resolução 196/96; os nomes referidos são pseudônimos escolhidos pelas entrevistadas.

\section{O contexto da criação do Instituto Federal de Educação, Ciência e Tecnologia do Paraná: a reorganização da Rede Federal de Formação Profissional}

Os embates que envolvem os projetos de formação profissional no Brasil, implantados a partir do Estado, expressam em cada contexto os projetos societários estabelecidos para o país. Ao tomarmos como base as discussões engendradas a partir da instauração da República, estendidas ao longo do século XX, as questões de formação profissional surgem atreladas ao ideal de modernização consideradas imprescindíveis para o desenvolvimento do país, na perspectiva capitalista (IANNI, 2001; MACHADO, 1998). A criação dos Institutos Federais de Educação, Ciência e Tecnologia do Paraná, como instituições de educação superior, básica e profissional, se insere no contexto da retomada do projeto de formação técnico-profissional vinculado à escolarização, implantada pelo governo Lula no início do século XXI, movimento posterior ao desmantelamento do sistema federal de ensino técnico pela política educacional de Fernando Henrique Cardoso, nos anos de 1990 (LIMA FILHO,2003).

Divers@ Revista Eletrônica Interdisciplinar/Matinhos/Vol.5, n.2, p.1-136/jul./dez./2012 
Alguns desses institutos integraram os Centros Federais de Educação Tecnológica e as Escolas Técnicas ou Agrotécnicas já existentes, outros derivaram das Escolas Técnicas vinculadas às Universidades Federais, caso do IFPR, que nasce do antigo setor da Escola Técnica da Universidade Federal do Paraná, no final de 2008. Caracterizada como uma política de descentralização, os Institutos Federais tem uma estrutura multicampi. Nessa perspectiva, em agosto de 2008, foi inaugurado o campus Paranaguá do IFPR, localizado no litoral paranaense ${ }^{5}$, único Câmpus do Estado que se aproxima da proposta de verticalidade presente na lei de criação, tendo em vista que oferece Educação Básica, Ensino Superior (tecnólogo e licenciaturas) e Pós-graduação.

Não obstante entre as finalidades dos Institutos, esteja a preocupação com a consolidação e o fortalecimento dos arranjos produtivos sociais e as culturas locais, e haja, no texto da lei, uma grande ênfase na articulação entre o local, o regional e o nacional, ainda não há elementos que permitam avaliar em que aspecto tais questões são contempladas. Ezequiel Westphal e Clóvis Brondani (2009), assim descrevem o território onde a Instituição está instalada:

O Campus situa-se na periferia da cidade, em um bairro pobre, carente de infraestrutura e políticas públicas de apoio social. Os problemas maiores estão relacionados às áreas de ocupação de restingas e manguezais pelas famílias sem teto e dos moradores do conjunto habitacional, em torno das dificuldades de emprego, saúde, creches e outras demandas.

Apesar dessas características do entorno da região, perfil que pode ser estendido para o litoral paranaense, não podemos afirmar que essa é a população majoritária atendida na Instituição. Argumentamos que o fortalecimento do PROEJA seria um dos caminhos alternativos para a garantia de acesso de determinados grupos que ainda estão excluídos do acesso à formação oferecida nos Institutos. Atualmente, em relação aos cursos inseridos especificamente no PROEJA - Ensino Médio Integrado, com aulas ministradas diretamente no Campus, são oferecidos os cursos de Eletromecânica, composto por uma turma que totaliza 26 alunos, e nenhuma aluna, o curso PROEJA de Logística, com 12 alunos e 3 alunas. Os concluintes desses cursos obterão o diploma de Técnico em sua área.

\footnotetext{
${ }^{5}$ Formam o litoral paranaense os municípios de Antonina, Guaraqueçaba, Guaratuba, Matinhos, Morretes, Paranaguá e Pontal do Paraná. Ao tomarmos como base o Índice de Desenvolvimento Humano (IDH) dos municípios que compõem o litoral paranaense, este varia entre 0,659, em Guaraqueçaba, e 0,788 nos municípios de Pontal do Paraná e Antonina, em uma média de 0,787. A renda per capita média é de $\mathrm{R} \$ 237,40$.
} 
A outra forma de atendimento da Instituição ao PROEJA ocorre a partir do PROEJA FIC (Formação Inicial e Continuada) de Pesca e Aquicultura, campo de análise que será apresentada neste texto. O PROEJA/FIC, iniciou no $2^{\circ}$ semestre de 2010; destinado aos estudantes do ensino fundamental, constitui-se por um grupo formado por 16 alunas e 2 alunos, com uma faixa etária compreendida desde os 15 até os 60 anos de idade. As disciplinas do núcleo comum, que abrange inclusive a alfabetização, são ministradas pelo quadro docente do Município, enquanto as disciplinas específicas são de responsabilidade do IFPR - campus Paranaguá (eixo de recursos naturais).

Ao contrário dos/as concluintes do PROEJA Técnico Médio Integrado, este grupo não terá direito a um diploma, mas a um certificado, o que em termos de atuação profissional limita as possibilidades de inserção em determinados campos; o fato da maioria do grupo ser formado por mulheres, ao contrário, por exemplo, dos cursos oferecidos no Ensino Médio /PROEJA desenvolvidos no Câmpus, nos despertou especial interesse para o campo da pesquisa.

Para compreensão das especificidades desse Programa, apresentamos inicialmente a análise da legislação em qual este está amparado, para posteriormente apresentarmos os resultados da pesquisa desenvolvida junto aos alunos e alunas do PROEJA FIC de pesca e aquicultura.

\section{O PROEJA enquanto política educacional}

Conforme apontamos anteriormente, o PROEJA foi implantado pelo Governo Federal a partir do Decreto 5478/2005. De acordo com a análise de Frigotto, Ciavatta e Ramos (2005, p. 1096), os encaminhamentos estabelecidos nesse documento tinham como objetivos sanar os limites impetrados no decreto do governo anterior (Decreto 2208/1997), que fomentou uma formação aligeirada, dissociada da educação básica e de um plano de formação continuada; mas apesar de alguns avanços o Decreto de 2005 foi passível de críticas, gerando uma nova reformulação.

O documento base que apresenta o programa Nacional de Integração da Educação Profissional com a Educação Básica na modalidade de Educação de Jovens e Adultos, foi produzido primeiramente em 2006 e reelaborado em 2007, em função das alterações na Divers@ Revista Eletrônica Interdisciplinar/Matinhos/Vol.5, n.2, p.1-136/jul./dez./2012 
legislação (do Decreto 5.478/2005 para o Decreto $\mathrm{N}^{\mathrm{o}}$ 5.840/2007). O texto enfatiza a Educação de Jovens e Adultos como um campo de conhecimento específico, no qual se deve observar as necessidades próprias de aprendizagem, ligadas diretamente à realidade desses sujeitos. O que impõe uma proposta político pedagógica também específica.

Apresentadas essas concepções, o documento elenca os princípios que fundamentam a política de Proeja, entre os quais: Consideração das condições geracionais, de gênero, de relações étnico-raciais como fundantes da formação humana e dos modos como se produzem as identidades sociais. Em relação a esse aspecto apontado no documento, o comentário complementar expressa a perspectiva que deverá orientar os projetos a serem desenvolvidos:

\begin{abstract}
O sexto princípio considera as condições geracionais, de gênero, de relações étnicoraciais como fundantes da formação humana e dos modos como se produzem as identidades sociais. Nesse sentido, outras categorias para além da de "trabalhadores", devem ser consideradas pelo fato de serem elas constituintes das identidades e não se separarem, nem se dissociarem dos modos de ser e estar no mundo de jovens e adultos. (BRASIL, 2007, p.38)
\end{abstract}

Os aspectos apontados pelo documento, em especial em relação à somatória de fatores identitários que acentuam o processo de discriminação, não é a única referência feita às tais questões. Ao longo de texto apresentado, a preocupação com as questões de gênero está presente, por exemplo, ao ressaltar parte do percurso vivenciado por alunos e alunas que buscam o Programa:

Assim, mais tarde esses jovens retornam, via EJA, convictos da falta que faz a
escolaridade em suas vidas, acreditando que a negativa em postos de trabalho e
lugares de emprego se associa exclusivamente à baixa escolaridade, desobrigando o
sistema capitalista da responsabilidade que lhe cabe pelo desemprego estrutural. A
EJA, em síntese, trabalha com sujeitos marginais ao sistema, com atributos sempre
acentuados em consequência de alguns fatores adicionais como raça/etnia, cor,
gênero, entre outros. Negros, quilombolas, mulheres, indígenas, camponeses,
ribeirinhos, pescadores, jovens, idosos, subempregados, desempregados,
trabalhadores informais são emblemáticos repre
que a sociedade brasileira, excludente, promov COVOLAN; MACHADO
desfavorecida econômica, social e culturalmente. (BRASIL, 2UU /, p. grito nosso)

Nesse aspecto, enquanto o público atendido pelo PROEJA traz um histórico marcado pela desigualdade de acesso às oportunidades, tanto no âmbito da escolarização quanto na formação profissional, as relações de gênero ${ }^{6}$ construídas nesse processo acumulam o potencial de desigualdades estabelecidas, o que se estende para o mundo do trabalho. $\mathrm{O}$

\footnotetext{
6 A discussão das relações sociais de gênero é compreendida neste trabalho como categoria de análise histórica e social imprescindível para pensarmos as relações de poder na sociedade, estabelecidas pelas diferenças entre homens e mulheres, homens e homens e mulheres e mulheres (SCOTT, 1995).
}

Divers@ Revista Eletrônica Interdisciplinar/Matinhos/Vol.5, n.2, p.1-136/jul./dez./2012 
desenvolvimento da pesquisa em questão vem evidenciando os aspectos apontados no Documento, questões elucidadas a partir do trabalho de campo realizado com alunas e alunos do PROEJA FIC - pesca e aquicultura - das séries iniciais, do Município de Pontal do Paraná, resultado que passamos a apresentar a seguir. ${ }^{7}$

\section{O PROEJA FIC no IFPR/Paranaguá}

Como início do trabalho de campo, nos aproximamos do grupo a partir da observação de uma das aulas ministradas pelos docentes do eixo de Recursos Naturais, do IFPR, onde foi possível traçar um perfil inicial do grupo, além de estabelecer um primeiro vínculo com o universo pesquisado.

Enquanto processo metodológico, não obstante a pesquisa siga uma perspectiva qualitativa, destacamos a importância dos dados quantitativos como ponto de partida para questões que subsidiassem as demais fases da pesquisa, como o desenvolvimento de entrevistas realizadas posteriormente.

Nessa perspectiva, traçamos um desenho metodológico baseado na adoção da chamada triangulação metodológica, desenvolvido inicialmente por Pawson (MINAYO, 2005), onde há um pluralismo na adoção dos métodos e instrumentos de pesquisa para uma mesma investigação.

Dessa forma, o perfil discente foi elaborado a partir dos questionários aplicados para toda a turma presente, composta por 15 alunas e 2 alunos do PROEJA/FIC, em maio de 2012. Duas questões iniciais nos instigaram como dados de pesquisa - o fato das mulheres serem a grande maioria no curso, somada a especificidade da faixa etária - $80 \%$ do grupo feminino tem entre 39 e 63 anos, todas em fase de letramento.

A questão nos remete a afirmativa de Russell Parry Scott (2004), que indica o termo polissêmico, na interface entre "idade" e duas concepções inter-relacionadas de "geração". A perspectiva geracional é fundamental para os estudos relacionados ao PROEJA; em estudo acerca de gênero, pobreza e analfabetismo, o autor conceitua geração a partir da aproximação

\footnotetext{
7 A pesquisa também vem sendo desenvolvida com os alunos do PROEJA - Ensino Médio Integrado, grupo para o qual também foram aplicados questionários. No entanto, a opção neste artigo foi pela análise específica do perfil de alunas do PROEJA/FIC, séries iniciais.

Divers@ Revista Eletrônica Interdisciplinar/Matinhos/Vol.5, n.2, p.1-136/jul./dez./2012
} 
de experiências históricas vividas por um mesmo grupo, que em um nível macro se constitui como grupos etários. O autor adota essa definição para enfatizar as especificidades que atingem as mulheres acima de 35 anos de idade em relação ao analfabetismo, e aponta a necessidade de políticas públicas para esse grupo:

Os fatores geracionais históricos são de uma importância extraordinária neste período, pois as mulheres acima de 35 anos seriam candidatas a alfabetização na idade escolar nos anos 70 ou antes, e neste período houve menor acesso das mulheres à escola, bem como maiores proporções de pessoas morando no campo distante das escolas. (...) Como consequência destes processos as mulheres nas faixas etárias superior a em torno de 35 anos, analfabetas e residentes em arranjos familiares sem cônjuges, sofrem de dificuldades no mercado de trabalho pela sua desqualificação e também sofrem desafios para lidar com os efeitos dos eventos violentos e excludentes no curso de vida (...). Argumenta-se que, para promover a igualdade de gênero, as políticas educacionais deveriam ter componentes especiais favorecendo mulheres de faixas etárias superiores que incluam, além da própria alfabetização, reforço de autoestima e valorização frente aos eventos excludentes e violentos vividos por elas nas relações de gênero ao longo da vida. (SCOTT, 2004, p.3).

A perspectiva apontada pelo autor, delineada nos questionários aplicados para todo o grupo, foi ainda mais evidenciada nas entrevistas realizadas com as alunas entrevistadas. A origem das alunas também ratifica a afirmativa do autor, $60 \%$ nasceu na área rural, e $33 \%$ nasceu na área urbana. Ao perguntarmos onde elas passaram, até o momento, a maior parte de suas vidas, obtivemos os seguintes dados: 




Gráfico 1 - Onde passou maior parte da sua vida

A questão de grande parte da trajetória de vida dessas mulheres, em especial desde a infância, ter sido vivida na área rural, refletiu, em seus relatos, na limitação do acesso aos espaços escolarizados, e na priorização do trabalho frente a alguma possibilidade em estudar, e, no caso de uma das nossas entrevistadas, Pérola, hoje com 61 anos, em certa continuidade em relação a trajetória da própria mãe. Ao ser indagada sobre a infância e o acesso a Escola, menciona:

(...) O pouco que lembro a gente se crio embaixo dos pé de fumo, nossa infância mais foi trabalha, eu nasci atrás de uma arvore, quando a minha mãe estava voltando da roça pra casa. (...) eu chorava muito porque meu pai dizia que mulher não precisava estudar, eu só trabalhava na roça e cuidava das crianças (...) eu chorava quando minhas irmãzinhas iam pra escola e eu não, elas enfrentaram o pai e a mãe... era outra época, tinha escola mais perto. (Pérola, 61 anos).

Outro aspecto comum na trajetória das mulheres participantes da pesquisa é sua relação, desde a infância, com o trabalho doméstico. Responsável por essas funções em suas próprias casas, essa acaba por ser também a primeira experiência de grande parte do grupo como trabalho remunerado. 


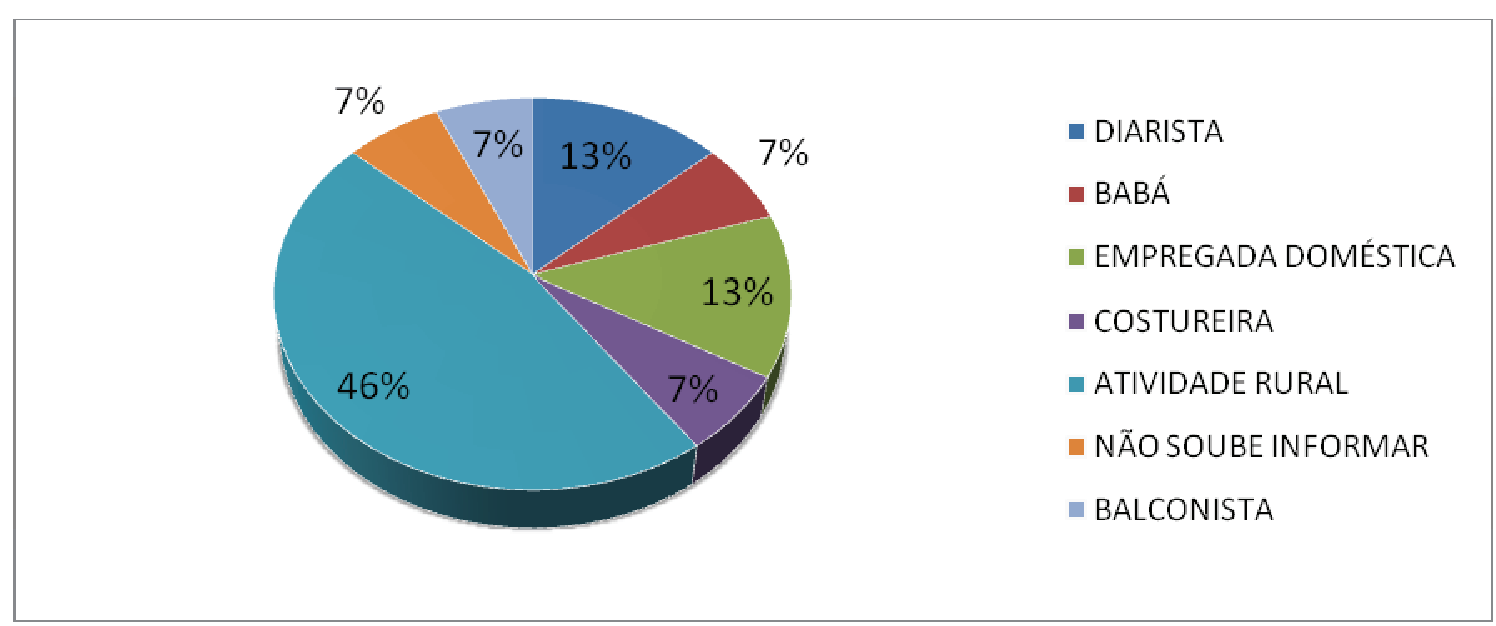

Gráfico $2-1^{\mathrm{a}}$ atividade remunerada exercida

Esse aspecto marca inclusive a transição da área rural para a cidade, conforme relata Pérola:

(...) com 14 anos, veio uma família lá na roça muito rica, que de passagem pela roça perguntou pro pai se ele deixava eu vir trabalhar com eles na cidade (...) eu não queria ir... mas fui.. .eu nunca dizia não, se pai ou mãe mandasse a gente se atirava no poço (...) então eu trabalhava na casa e cuidava das criança da mulher...de vez em quando eles me dava algum dinheiro (...) quando casei, continuei trabalhando lá só não dormia na casa. (Pérola, 61 anos)

A "adoção" de crianças do campo, geralmente meninas, por famílias urbanas em melhores condições financeiras, para que estas servissem como empregadas domésticas em troca de casa e comida é uma prática antiga no país, e ocorreu também com Marta:

(...) me deram pra essa família, com 8, 9 anos (...) eles me adotaram como filha (...) eu não tinha registro, nada, eles me registraram (...) ela (nome da mulher) saia e dizia pra mim, você faz pão, lava, encerra, passa escovão, quero ver tudo um brinco quando eu chegar (...) e se não tava bom eu apanhava (...) eu não ganhava nada, não, só surra (...) até fugir. (Marta, 59 anos)

A idade com a qual começaram a exercer o trabalho remunerado caracteriza nitidamente o trabalho infantil, considerando que aproximadamente $60 \%$ teve sua primeira ocupação antes dos 12 anos de idade. 


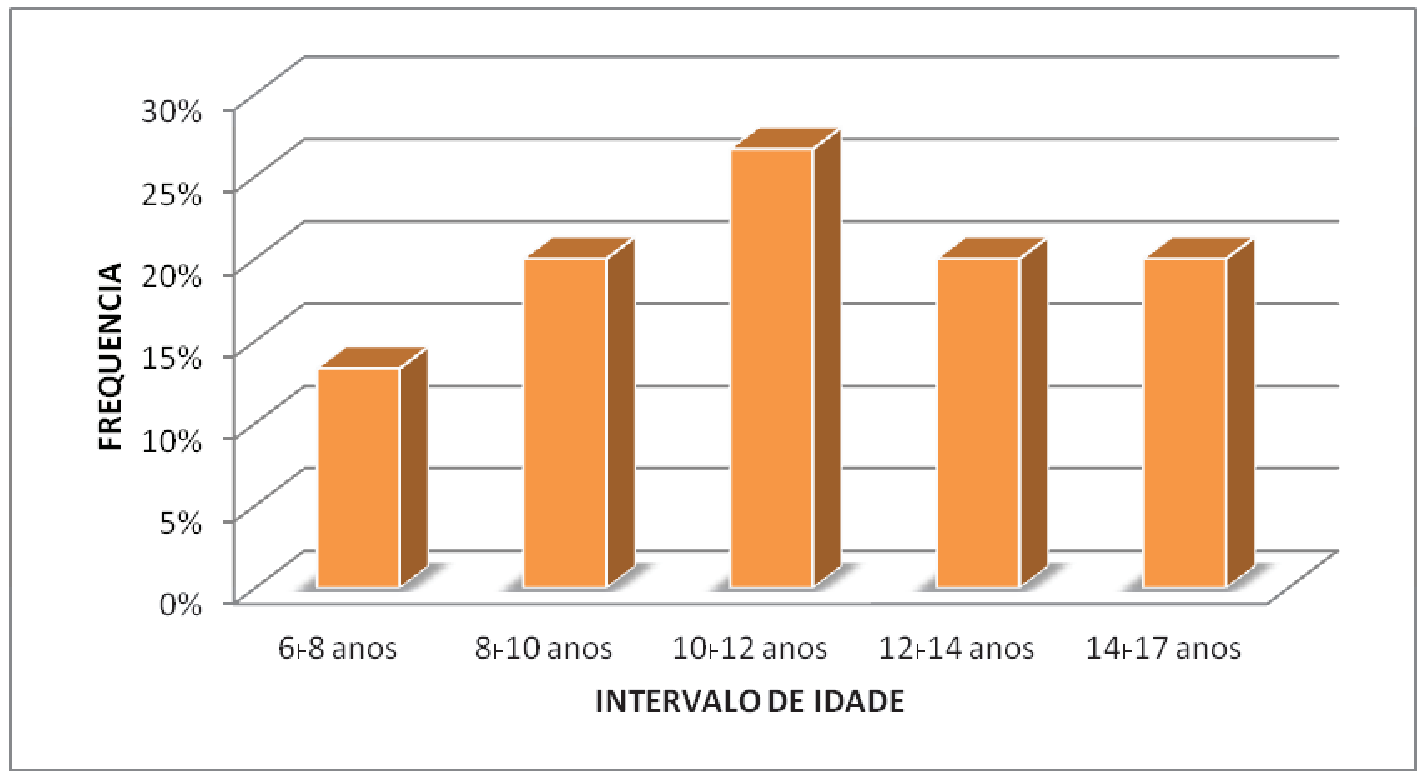

Gráfico 3 - Idade em que começou a trabalhar

A permanência em relação ao trabalho doméstico remunerado, e a precarização enquanto trabalho informal também caracteriza o grupo - $47 \%$ atualmente exerce trabalho doméstico remunerado e, dentre todas as que trabalham, 66 \% não possui carteira assinada, o que as exclui de qualquer direito trabalhista, com o agravante de que todas são mães, numa média de 3 a 4 filhos, sendo que 47 \% são chefes de família.

Ao analisarmos os indicadores do Município em que o grupo envolvido na pesquisa reside, constatamos que no ano de 2010, a participação da mulher no mercado de trabalho formal chegava a $44,8 \%$, e o percentual do rendimento feminino em relação ao masculino era de $86,1 \%$ em 2010 , independentemente da escolaridade. ${ }^{8}$

Helena Hirata (2002, p.280), argumenta que a divisão social e técnica do trabalho é acompanhada de uma hierarquia clara do ponto de vista das relações sexuadas de poder. A autora destaca ainda como essas assimetrias são marcadas pelas permanências (2003, p.20):

\begin{abstract}
Na realidade, embora mudanças e continuidades coexistam, o deslocamento hoje das fronteiras do masculino e do feminino deixa intacta a hierarquia social que confere superioridade ao masculino sobre o feminino, hierarquia sobre a qual (...) se assenta a divisão sexual do trabalho. Enquanto a "conciliação" entre vida profissional e vida familiar, trabalho assalariado e trabalho doméstico for pertinente exclusivamente para as mulheres, as bases em que se sustenta essa divisão sexual não aparecem ameaçadas nos seus fundamentos.
\end{abstract}

\footnotetext{
${ }^{8}$ Dados disponibilizados pelo portal ODM - Objetivos de Desenvolvimento do Milênio, disponível em www.portalodm.com.br

Divers@ Revista Eletrônica Interdisciplinar/Matinhos/Vol.5, n.2, p.1-136/jul./dez./2012
} 
Nesse aspecto, enquanto o público atendido pelo PROEJA - homens e mulheres - traz um histórico marcado pela desigualdade de acesso às oportunidades, tanto no âmbito da escolarização quanto na formação profissional, as relações de gênero construídas nesse processo e as assimetrias entre homens e mulheres acumulam o potencial de desigualdades estabelecidas, o que se estende para o mundo do trabalho.

Dessa forma, constatamos nos relatos semelhanças quanto a trajetória de vida, tais como a origem rural, as famílias numerosas, a divisão sexual do trabalho desde a infância, a ida para a cidade ainda na pré-adolescência para trabalhar em casas de família, como também o abandono dos companheiros e a luta para sobreviver e manter os filhos e filhas, além do esforço para que os filhos e filhas estudassem, para concretizar o acesso a um direito que a elas foi negado.

Nesses contextos, é comum ainda a falta de oportunidade para estudar, e, ao contrário da ideia que tínhamos no início da pesquisa, não se trata de um grupo que abandonou a Escola, mas sim, de um que nunca teve acesso a ela, e neste momento de suas vidas buscaram o direito que lhes foi negado, a começar pelo desejo de se alfabetizarem.

O que motivou essas mulheres a essa busca? Qual o significado dessa conquista para o grupo? Marta (59 anos) teve sete entre filhos e filhas e atualmente mora com uma de suas filhas que ainda depende dos seus cuidados, numa casa que constrói aos poucos. Narra sua vida, passada em meio a privações e violências físicas, e a realização, ha pouco mais de dois anos, do sonho de aprender a ler e a escrever, assim como os desdobramentos desse aprendizado. Ao perguntarmos sobre o que a motivou a buscar a Escola nesse momento de sua vida, ela aponta a bíblia sobre a mesa e argumenta:

\footnotetext{
Aí eu comecei a ler e escrever aqui ó...na bíblia, sozinha! Quando eu entrei na Universal (Igreja) eu queria fazer proposta e não conseguia, aí eu pedia pra minha filha - proposta é assim, é escrever - você quer que Deus te abençoe? Aí você tinha que escrever lá o pedido no papel, colocar dentro do envelope e colocar o dinheiro. Isso é errado né, Deus não cobra, mas a Igreja pedia. Aí eu pedia pras minhas filhas e elas diziam: Como que a senhora me dá todo esse dinheiro na Igreja? É um absurdo! A senhora não pode fazer isso - ai me criticavam. Aí eu dizia - Senhor, eu tenho que fazer as minhas coisas e ficar dando satisfação pros meus filhos? Então o senhor tem que me ensinar eu fazer sozinha sem precisar ficar pedindo pra filho. Eu dei estudo pros meus filhos e hoje eles não podem me ajudar? Ai eu comecei a escrever sozinha, ler a bíblia e escrever. Quando eu cheguei aqui (no Litoral) eu falei :Senhor, eu vou estudar, e procurei a Escola . (Marta, 59 anos)
} 
A questão da religião como fator motivacional para a aprendizagem da leitura é um tema instigante e recorrente nas pesquisas acerca de alunas da Educação de Jovens e Adultos, Vera Lúcia Nogueira ( 2006, p.80), também encontrou nos depoimentos de suas entrevistadas a justificativa da leitura da Bíblia, ou de uma participação mais efetiva na Igreja como fator inicial que as impulsionou na busca pela Escola.

Para além das críticas pertinentes sobre a relação entre a religião e exploração econômica, no caso da entrevistada Marta, o que nos interessa é o fator motivador comum entre essas mulheres na busca do espaço escolar - sair de uma situação de dependência em várias circunstâncias para um processo de empoderamento.

A adoção do conceito de "empoderamento" exige a indicação do referencial a ser tomado para a pesquisa. Termo de origem inglesa, este pode adquirir múltiplos significados de acordo com os projetos políticos acionados em cada contexto, conforme aponta Maria da Glória Gohn (2004,p.23) :

\begin{abstract}
Cumpre destacar que o significado da categoria "empowerment" ou empoderamento como tem sido traduzida no Brasil, não tem um caráter universal. Tanto poderá estar referindo-se ao processo de mobilizações e práticas destinadas a promover e impulsionar grupos e comunidades - no sentido de seu crescimento, autonomia, melhora gradual e progressiva de suas vidas (material e como seres humanos dotados de uma visão crítica da realidade social); como poderá referir-se a ações destinadas a promover simplesmente a pura integração dos excluídos, carentes e de mandatários de bens elementares à sobrevivência, serviços públicos, atenção pessoal etc., em sistemas precários, que não contribuem para organizá-los - porque os atendem individualmente, numa ciranda interminável de projetos de ações sociais assistenciais.
\end{abstract}

Com base nas definições apontadas pela autora, assumimos a primeira perspectiva como o viés de análise, compreendendo o termo "empoderamento" como "fortalecimento", tradução que vem sendo aplicada por autores/as na tradução para a língua portuguesa, conforme destacam Maria Kleba e Agueda Wendausen (2009, p. 736): Significa aumento do poder, da autonomia pessoal e coletiva de indivíduos e grupos sociais nas relações interpessoais e institucionais, principalmente daqueles submetidos às relações de opressão, discriminação e dominação social.

Encontramos nos argumentos de Alda da Motta (1999, p.209) uma análise próxima ao perfil das entrevistadas, em relação a diferente trajetória de homens e mulheres no que se refere a categoria geração: Para as mulheres, a prescrição tradicional foi: domesticidade e 
maior repressão social e sexual, desestímulo ou dificuldade de acesso e permanência no mercado de trabalho, desigualdades de formação e de condições de trabalho em relação às dos homens. Por outro lado, a autora aponta que é justamente na velhice que essas mulheres retomam o que lhes foi tirado na juventude, pois buscam a autonomia, diante de um controle menor se comparado ao período da juventude.

Ao partir desses referenciais, formulamos no questionário a pergunta sobre o significado em estar estudando para essas mulheres. É relevante o fato de palavras como conquista, liberdade e valorização se destacarem nos apontamentos das entrevistadas.

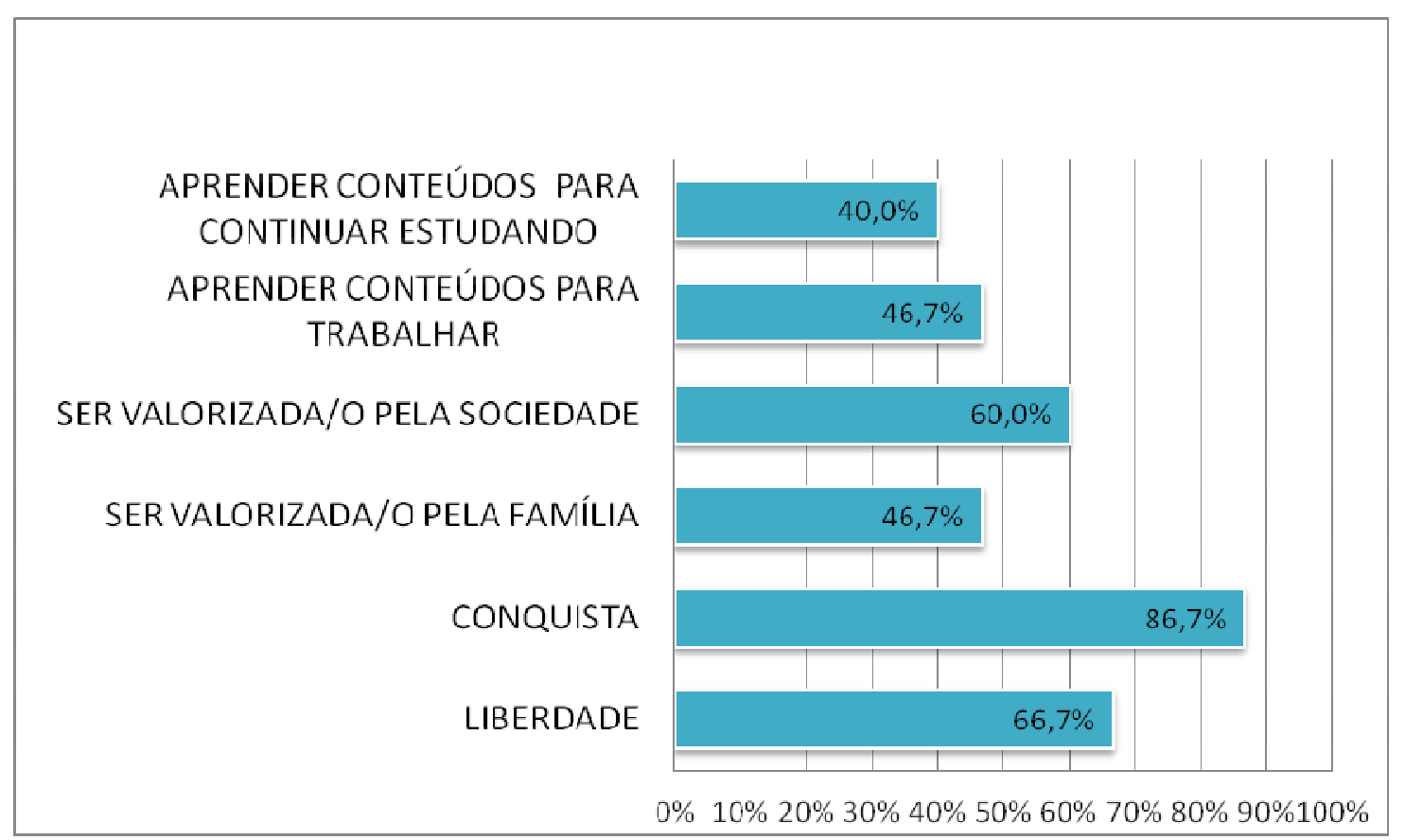

Gráfico 4 - o que significa para você estar estudando?

Na sua obra Desenvolvimento Como Liberdade, Amartya Sen (2010) apresenta uma abordagem de desenvolvimento, visto como um processo de expansão das liberdades substantivas das pessoas. Discute essa abordagem para as politicas públicas, econômicas e sociais. Refere uma formação de valores e a emergência da Ética social como partes do desenvolvimento que demanda atenção, junto ao funcionamento dos mercados e outras instituições. Uma característica da liberdade seria possuir aspectos que se relacionam a uma variedade de atividades e instituições. Na verdade, a liberdade substantiva das pessoas, notadamente das mulheres, seria o principio organizador do desenvolvimento, este visto como compromisso com as possibilidades de liberdade. Nesse contexto, é ilustrativa a resposta de Divers@ Revista Eletrônica Interdisciplinar/Matinhos/Vol.5, n.2, p.1-136/jul./dez./2012 
Marta referindo o nome da escola que frequenta, ao ser perguntada sobre a importância de estudar nesse momento:

“O Matusi me deu VIDA!" (...) a melhor coisa que aconteceu na minha vida foi aprender a ler e a escrever; eu me sinto uma mulher mais capaz, mais inteligente (...) minha família sente muito orgulho de mim (...) as pessoas me ve mais madura, mais cabeça, sabendo mais das coisas, mais esperta, ativa... o estudo é tudo (Marta, 59 anos)

De modo semelhante, referiu Pérola:

“mudou tudo eu ir pra escola... pude realizar meu sonho (...) poder, pra mim, é fazer aquilo que gosto, que entendo, que quero para mim, sem depender os outros. Agora eu posso" (Pérola, 61 anos)

No caso das mulheres estudantes, contou, para a realização do sonho da alfabetização, a maior liberdade adquirida com o tempo, para cuidar de si e agir sem a interferência de pais, mães, maridos, filhos. Para Amartya Sen (2010, p.100), a renda de um ou mais membros de uma família são compartilhadas por todos, por quem ganha e por quem não as ganha. O bem estar ou liberdade das pessoas na família dependem do modo como essa renda é usada na promoção dos interesses e objetivos dos membros. As regras de distribuição se relacionam ao sexo, idade, necessidades percebidas, e podem fazer grande diferença.

No caso das pesquisadas, estudar foi possível no momento em que não havia mais a necessidade delas garantirem a subsistência de filhos e filhas e também, essa escolaridade tardia, para além do saber ler e escrever significa, no limite, ser capaz de realizações próprias, autônomas, ou seja, empoderamento:

"Poder para mim é em primeiro lugar acreditar em Deus e correr atrás dos sonhos... a escola me deu poder, hoje eu me sinto outra pessoa, em dois anos to na 5 serie, imagine, eu na $5^{\text {a }}$ série!! (Marta, 59 anos)

Nesse sentido, a liberdade é um bem conquistado árdua e tardiamente, pelas estudantes; agora livres também de acatar proibições, repensam tradições sobre o modo como as mulheres são tratadas:

"Eu diria pras mulheres que assim, se alguma coisa elas não pode ser feita lá atrás, que ela vá atrás agora, mas tem que se informar, tem que sair de casa, perguntar.... a 
mulher pode fazer tudo (....) eu quis aprender a fazer crochê, e aprendi, a aprender a ler, aprendi, eu não vou parar" (Marta, 58 anos).

Algumas falas valorizam certas condições locais e postas pela política da educação voltada para este segmento:

\begin{abstract}
"mas isso eu consegui aqui.. se tivesse em Curitiba não dava, não tinha ônibus perto, tinha que pagar para ir de ônibus (...) aqui tem ônibus de graça, janta muito boa, até engordei um monte" (risos). (Marta, 59 anos)
\end{abstract}

Observações críticas pontuais também estão presentes nas falas das estudantes, como, por exemplo, a política de fechamento de algumas turmas de EJA em Escolas Municipais, para centralização em uma única Escola, nem sempre próxima a parte do grupo de estudantes:

\footnotetext{
“ (...) ia eu, minha vizinha e minha nora que tava na sétima série, já (...) nóis ia a pé e voltava, junto (...) era longe mas nós ia junto, então animava, tinha que ter mais grupos, tem sala de varde de noite aqui perto, a escola não precisa ser tão longe". (Perola, 61 anos)
}

Para Amartya Sen (2010), o desenvolvimento propriamente dito se dá pela eliminação de privações de liberdades substanciais que limitam as escolhas e as oportunidades das pessoas de exercerem sua condição de agentes. Nesse contexto, liberdades econômicas e politicas se reforçam, sendo que, no caso, a oportunidade de educação complementa outras individuais de participação econômica e politica e favorecem iniciativas para vencer privações. Como diz Marta:

“ (...) hoje eu vendo produtos de beleza, roupas, semi jóias, faço contas (...) to fazendo esta casa “. (Marta, 59 anos)

Corroborando Amartya Sen, a educação age em prol do prestígio social da mulher, seu potencial para ser independente, seu poder de expressar-se bem, seus conhecimentos sobre o mundo fora de casa, sua habilidade para influenciar as decisões do grupo. (SEN, 2010, p.282). Assim, facilidades econômicas politicas, sociais, segurança são direitos que, encadeados, correspondem a múltiplas liberdades inter-relacionadas: os fins e os meios do desenvolvimento exigem que a perspectiva da liberdade seja colocada no centro do palco. (SEN, 2010, p. 77).

Nesse contexto, as entrevistadas delineiam as expectativas futuras, no que se refere ao prosseguimento dos estudos: 


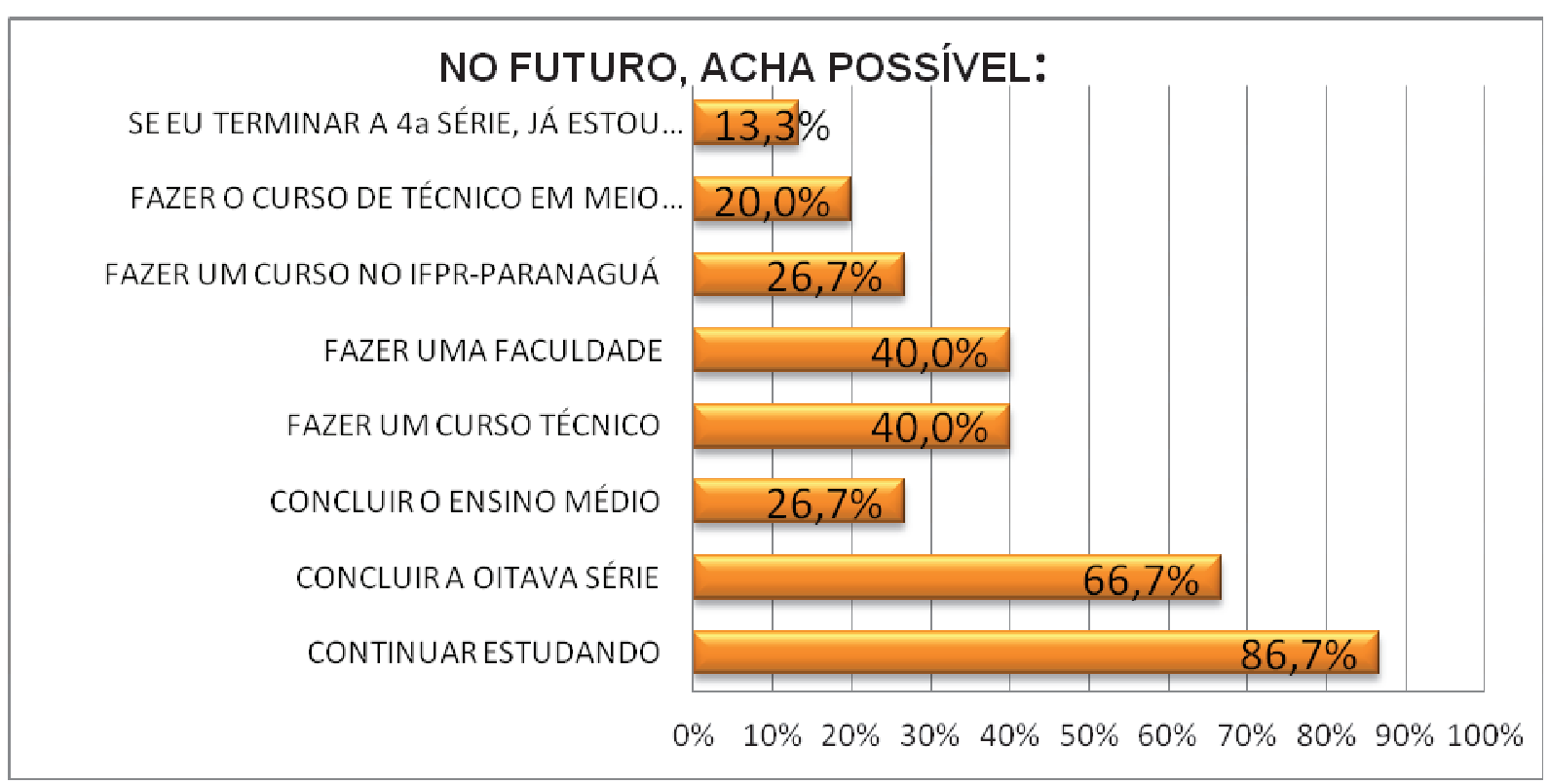

Gráfico 5 - No futuro você acha possível?

Assim se refere Pérola ao ser perguntado sobre seus planos para o futuro:

" eu quero fazer uma faculdade, um curso pra mim ser como um engenheiro, assim, que cuida de plantas, flores... tipo um agrônomo” (Pérola, 61 anos)

“agora eu sei que através do pouco que estudei, posso ir adiante (...) não vou parar, agora, semana que vem, vou me matricular na auto escola (...) agora sei ler, agora eu posso" (Marta, 59 anos).

De acordo com Sen (2010), por meio da independência e do ganho de poder potencial para auferir rendas fora da família, alfabetização e instrução - mesmo a desvantagem feminina na questão da sobrevivência em comparação com os homens parece diminuir drasticamente, quando há progresso da condição de agente nesses aspectos. Essa perspectiva também é respaldada pela pesquisa de Vera Lúcia Nogueira (2006), que destaca a necessidade de um olhar mais atento acerca da formulação das políticas públicas para esse grupo de mulheres, tendo em vista questões que vão além da preocupação com aspectos relacionados a filhos ou familiares:

(...) é preciso rever os argumentos que sustentam os investimentos das políticas educacionais destinadas às mulheres, principalmente às mulheres das camadas populares.(...) há fatores subjetivos e objetivos, que se encontram presentes nas motivações para a busca de escolarização, que extrapolam aquilo que se espera 
como efeito social, especialmente sobre a escolarização dos filhos e a saúde da família, pois tratam da concretização dos desejos de realização pessoal, de materialização de projetos individuais que subsistem ( ou que tentam subsistir) aos conflitos de gênero, inerentes à condição feminina e às relações familiares. (NOGUEIRA, 2006, p.86, grifos nosso)

Os dados levantados em nossa pesquisa vem reforçar esse aspecto, as entrevistadas, ambas numa faixa etária próxima dos 60 anos, evidenciaram que a busca da escolarização é um projeto pessoal, individual, para atender aos seus anseios; nenhuma delas mencionou a busca da escolarização para auxiliar família ou filhos, fator importante no que se refere a desnaturalização do papel da mulher enquanto mãe, ou, na representação de um grupo voltado para a subserviência e o cuidado do outro.

\section{Considerações finais}

Em nossa sociedade, de muitas formas, as oportunidades dependem de como funcionam e se inter-relacionam as instituições, o mercado, as políticas públicas, a mídia e as condições dos contextos individuais e dos grupos sociais. A educação é imprescindível para que as pessoas acessem desde informações pertinentes quanto direitos e bens socialmente produzidos para atender necessidades básicas.

No caso das mulheres pesquisadas - excluídas por vários motivos da educação formal - o fato de frequentar uma escola, aprender a ler e escrever e fazer contas, mesmo tardiamente, alavancou, especialmente, capacidades reprimidas de transformação pessoal, na realização de "sonhos" longamente adiados por vários contextos de privações. As imbricações desse encontro com a autonomia e o fator geracional, ratifica a perspectiva de Motta (1999) apontada anteriormente - mulheres próximas aos 60 anos, que após uma trajetória de olhar para os outros voltam-se para si, tendo em vista estarem desobrigadas de cumprir os papeis femininos naturalizados que desempenharam ao longo da vida, seja cuidar do marido ou de filhos.

Outro aspecto fundamental na pesquisa é a importância das políticas públicas voltadas para a Educação de Jovens e Adultos. As possibilidades oferecidas pelo Município enquanto transporte escolar, alimentação, auxilia na permanência na Escola. 
Em relação à especificidade do PROEJA/FIC, desenvolvido em parceria com o Instituto Federal do Paraná, alguns pontos se destacam, desde o oferecimento de uma bolsa no valor de $\mathrm{R} \$ 100,00$, embora com pagamentos instáveis, reforçaram a participação de alunas e alunos; ao mesmo tempo gerou uma expectativa junto ao grupo em ter acesso a essa Instituição, extremamente valorizada na região, pela sua representatividade federal. Este é um dos desafios da Rede Federal de Ensino, em especial os Institutos Federais, a partir dos cursos que oferecem educação básica e formação profissional. Ampliar o número de vagas para alunos do PROEJA, promover facilidades no acesso aos cursos, desenvolver um processo pedagógico que procure garantir a permanência de alunos e alunas, atender a legislação que estabelece o mínimo de $10 \%$ de suas vagas para esse Programa, são algumas das ações que podem efetivamente, colaborar no processo de empoderamento de determinados grupos que tiveram seus direitos mínimos negados em sua trajetória de vida.

\section{Referências}

Anais: XIV Encontro Nacional de Estudos Populacionais, ABEP, Caxambú - MG - Brasil, de 20- 24 de Setembro de 2004.

BRASIL, MEC. Documento Base PROEJA, 2007. Disponível em: http://portal.mec.gov.br/setec/arquivos/pdf2/proeja_medio.pdf> Acesso em: 20 mai. 2011.

FRIGOTTO, G; CIAVATTA, Maria; RAMOS, Marise. A Política de Educação Profissional no Governo Lula: Um percurso histórico controvertido. In: Educação e Sociedade, Campinas, vol. 26, n. 92, p. 1087-1113, out. 2005. Disponível em: $<$ http://www.cedes.unicamp.br>. Acesso em 2010.

GOHN, M. Empoderamento e participação da comunidade em políticas sociais. In:Saúde e Sociedade, São Paulo, v. 13, n. 2, p. 20-31, mai./ago. 2004.

HIRATA, Helena. Tecnologia, formação profissional e relações de gênero no trabalho. Revista Educação e Tecnologia, p.144-156, 2002. Disponível em: <www.ppgte.cefetpr.br/publicações.htm>. Acesso em: mar. 200'

COVOLAN; MACHADO

IANNI, Octavio. Teorias da Globalização. Rio de Janeiro: Civilização Brasileira, 2001.

KLEBA, M. E; WENDAUSEN, A. Empoderamento: Processo de fortalecimento dos sujeitos nos espaços de participação social e democratização política. In: Saúde e Sociedade: São Paulo, v.18, n.4, p.733-743, 2009. 
LIMA FILHO, Domingos L. A desescolarização da escola: impactos da reforma da educação profissional (período de 1995 a 2002). Curitiba: Torre de Papel, 2003.

MACHADO, Lucília R. de Souza. Educação e Divisão Social do Trabalho: Contribuição para o estudo do ensino técnico industrial brasileiro. São Paulo: Cortez, 1998.

MINAYO, Maria Cecília de Souza (org.). Avaliação por triangulação de métodos: abordagem de programas sociais. Rio de Janeiro: Editora FIOCRUZ,

2005.

MOTTA, Alda Brito da. As dimensões de Gênero e Classe Social na análise do envelhecimento. Cadernos Pagu (13).Campinas:1999,p. 191-221.

NOGUEIRA, Vera Lucia. Educação de Jovens e Adultos e Gênero: um diálogo imprescindível à elaboração de políticas educacionais destinadas às mulheres das camadas populares. P. 65-90. In: SOARES, Leôncio (Org). Aprendendo com a diferença - estudos e pesquisas em educação de jovens e adultos. Belo Horizonte: Autentica. 2006.

RESOLUÇÃO 196/96. http://www.bioetica.ufrgs.br/res19696.htm. Acesso em maio 2012.

SCOTT, Russell Parry. Monoparentalidade, analfabetismo e políticas de gênero e geração. http://www.abep.nepo.unicamp.br/site_eventos_abep/PDF/ABEP2004_709.pdf; acesso em março 2012.

SEN, Amartya. Desenvolvimento como Liberdade. São Paulo: Companhia das Letras, 2010.

WESTFHAL, Ezequiel; BRONDANI, Clóvis. Formação continuada e humanística de alunos do PROEJA: A perspectiva interdisciplinar do IFPR/ Campus Paranaguá. In: III Simpósio Nacional de Tecnologia e Sociedade: Desafios para a Transformação Social.Curitiba: UTFPR, Nov.2009. 